\title{
Responsabilidade social e ambiental: um estudo de caso em uma empresa de tecnologia em Porto Alegre
}

\begin{abstract}
Resumo
Este artigo tem como objetivo analisar a aplicação dos conceitos de sustentabilidade e responsabilidade social na gestão de uma empresa de tecnologia da informação e comunicação. Para atender a este objetivo, foram obtidas informações sobre o tema na literatura, foi realizada uma entrevista semiestruturada com os servidores da empresa em estudo, além da análise de documentos e de materiais impressos disponibilizados pela companhia. Esta pesquisa busca demonstrar a importância da gestão sustentável, voltada para a responsabilidade das empresas em garantir sua sobrevivência, sem que isso comprometa as gerações futuras. Assim, a correta administração de recursos e a consciência em preservar o meio ambiente são fatores importantes a serem considerados pelas organizações. Com a crescente preocupação da sociedade em torno de ações que minimizem danos ao meio ambiente, as empresas de tecnologia da informação também estão se conscientizando e aderindo a meios mais sustentáveis de trabalho. Portanto, através dos resultados desta análise, foi possível perceber que as empresas estão se preocupando cada vez mais com a conservação do meio ambiente. A preocupação da companhia é criar ambientes de trabalho mais verdes, priorizando ações sustentáveis. Assim, as principais atitudes implementadas a partir do conceito verde são economia de energia, descarte adequado de componentes eletrônicos e utensílios tecnológicos, adotando hábitos sociais embasados na sustentabilidade.
\end{abstract}

Palavras-chave: Gestão. Responsabilidade Social. Tecnologia. Sustentabilidade. Meio Ambiente.

\begin{abstract}
This article aims to analyze the application of the concepts of sustainability and social responsibility in the management of a company's information technology and communication. To meet this objective, we obtained information on the topic in the literature, we performed a semi-structured interview with the servers of the company under study, as well as analysis of documents and printed materials provided by the company. This research seeks to demonstrate the importance of sustainable management, focused on corporate responsibility to ensure their survival without compromising future generations. Thus, the correct administration of resources and awareness to preserve the environment are important factors to be considered by organizations. With the growing concern of society around the actions that minimize damage to the environment, business information technology are also becoming aware of and adhering to more sustainable means.
\end{abstract}

\footnotetext{
${ }^{1}$ Acadêmica do Curso de Administração das Faculdades Integradas de Taquara - Taquara/RS (FACCAT).nandabier@gmail.com.

2 Doutoranda no Programa de Pós-Graduação em Desenvolvimento Regional (PPGDR) da Universidade de Santa Cruz (UNISC). Professora das Faculdades Integradas de Taquara Taquara/RS (FACCAT). dilanib@faccat.br.
} 
Therefore, through the result of this analysis, it was possible to see that companies are increasingly concerned with environmental conservation. The concern of the company is to create work environments, greener, prioritizing sustainable actions. Thus, the main actions implemented from the green concept are: energy saving, proper disposal of electronic components and technological tools, adopting social habits grounded in sustainability.

Keywords: Management. Social responsibility. Technology. Sustainability. Environment.

\section{Introdução}

Este artigo tem como tema central as questões que envolvem a Gestão Sustentável e a Responsabilidade Social nas empresas na atualidade. Diante da evolução destes assuntos no mundo dos negócios, há uma crescente preocupação por parte das empresas em compreender esse conceito e incorporá-lo à realidade. Além disso, através desta pesquisa, busca-se a resposta para o seguinte questionamento: de que forma a empresa em estudo está se apropriando dos conceitos de sustentabilidade e responsabilidade social e inserindo-os na rotina de trabalho?

Dessa forma, a pesquisa busca demonstrar a importância da gestão sustentável, voltada para a responsabilidade das empresas em garantir sua sobrevivência, sem comprometer as gerações futuras. Assim, a correta administração de recursos e a consciência em preservar o meio ambiente são fatores importantes a serem considerados pelas organizações.

A empresa objeto deste artigo atua no ramo da tecnologia da informação e comunicação. É uma organização sólida, de médio porte, que opera no mercado há bastante tempo. Sua localização é na cidade de Porto Alegre, capital do Rio Grande do Sul.

A gestão anterior foi responsável pela implantação de um programa de sustentabilidade, que tem por objetivo fazer com que as tecnologias sejam transferidas para os setores público e privado, de forma mais eficiente e com menor impacto ambiental, por meio de iniciativas direcionadas aos seus principais segmentos de atuação, que são software ${ }^{3}$, hardware ${ }^{4}$, datacenter ${ }^{5}$, redes e gestão administrativa. Esta iniciativa busca seguir a tendência mundial de TIC verde, ou seja, qualificar a empresa com responsabilidade ambiental e promover a racionalização de custos e energia.

No sentido de contribuir para os estudos da prática sustentável, este trabalho objetivou demonstrar como a companhia está incorporando a sustentabilidade em sua gestão, tendo como objetivo geral analisar a aplicação dos conceitos de responsabilidade social e sustentabilidade na administração da empresa, e, como objetivos específicos, caracterizar os conceitos de desenvolvimento sustentável e responsabilidade social, identificar as ações sustentáveis executadas pela empresa e comparar os modelos de gestão sustentável citados na literatura com o processo encontrado na empresa pesquisada.

Quanto aos procedimentos metodológicos, a pesquisa tem caráter exploratório

\footnotetext{
${ }^{3}$ Software: são programas de computadores, utilizados para executar várias tarefas.

${ }^{4}$ Hardware: é toda a parte física que compõe um computador, ou seja, são as peças internas.

${ }^{5}$ Datacenter: são instalações que contêm equipamentos eletrônicos utilizados para processamento, armazenamento de dados e comunicações de redes, que se tornaram comuns e essenciais ao funcionamento das empresas, centros acadêmicos e sistemas de governo (WANDERS, 2011).
} 
e descritivo, com abordagem qualitativa, acompanhada de uma revisão bibliográfica. Quanto aos procedimentos técnicos, foi utilizado o método de estudo de caso. Este teve como objeto de pesquisa uma empresa do ramo de tecnologia da informação, reconhecida como organização que tem empreendido esforços para enquadrar-se como empresa sustentável.

A coleta de dados foi obtida por meio de entrevista semiestruturada com os coordenadores da assessoria executiva e de comunicação e com o supervisor do setor de recursos humanos da companhia; além disso, foi aplicado um questionário fechado com os funcionários da empresa. Outras informações foram obtidas por meio de materiais publicados, como, por exemplo, os relatórios de gestão elaborados anualmente, e, quanto aos dados coletados, serão analisados e interpretados por meio de análise de conteúdo.

O presente artigo está dividido em quatro capítulos. O primeiro será dedicado ao entendimento dos significados e das implicações da responsabilidade social. Nesta etapa, será apresentado o conceito de responsabilidade social e empresarial, e as ações das empresas em relação às demandas sociais.

No segundo capítulo, o tema em destaque é a gestão sustentável, no qual se destaca a importância de atitudes e práticas sustentáveis em uma empresa.

O terceiro capítulo tem como tema um assunto bem atual: a tecnologia sustentável. Neste, o objetivo é apresentar a implantação de procedimentos tecnológicos que têm como meta reduzir os impactos no meio ambiente.

E o quarto capítulo discorre sobre a importância da sustentabilidade na gestão empresarial, nele são apresentadas as análises dos resultados obtidos através das entrevistas.

\section{Responsabilidade social}

A responsabilidade social se apresenta como um tema cada vez mais relevante para o comportamento das empresas, sejam elas do setor público ou privado, influenciando nos objetivos e nas estratégias das organizações.

Segundo Donaire (1999, p. 20), pode-se definir responsabilidade social "[...] como compromisso que uma organização assume perante a sociedade por meio de atos e atitudes que afetam positivamente, de modo amplo ou específico, a sua prestação de contas para com ela".

Segundo a Associação Brasileira de Normas Técnicas (2013) - NBR ISO 26000:2010, o termo responsabilidade social tornou-se amplamente usado, no início da década de 70 , embora vários aspectos da responsabilidade social já fossem objeto da ação de organizações e do governo desde o final do século XIX. Atualmente, existem vários fatores que podemos citar como ações de responsabilidade social, mas o principal deles atinge diretamente a imagem da empresa perante a sociedade em que está inserida, e também as partes interessadas. Sob esse aspecto, as partes interessadas, ou stakeholders, como são chamadas, são indivíduos ou grupos afetados pelo desempenho de uma organização, como público interno, clientes, fornecedores, acionistas, comunidade, governo e sociedade (FREEMAN, 1984).

Por conseguinte, a responsabilidade social também pode ser denominada de 
responsabilidade empresarial, conforme definição do Instituto de Empresa e responsabilidade Social - Instituto Ethos (2013), que define: responsabilidade social empresarial como forma de gestão que se define pela relação ética e transparente da empresa com todos os públicos com os quais ela se relaciona e pelo estabelecimento de metas empresariais compatíveis como o desenvolvimento sustentável da sociedade, preservando recursos ambientais e culturais para as gerações futuras, respeitando a diversidade e promovendo a redução das desigualdades sociais.

Todavia, a responsabilidade social nas empresas significa que a organização precisa reconhecer os impactos causados por seus produtos, processos e instalações, apresentando algumas ações isoladas, no sentido de minimizá-los. Eventualmente, busca promover o comportamento ético (TACHIZAWA, 2008).

Sendo assim, praticar responsabilidade social ou responsabilidade empresarial significa que a empresa passa a ter uma posição ética, adquirindo uma visão ampliada do negócio, não considerando somente seus objetivos econômicos e comerciais, mas se preocupando com o impacto de seus produtos e serviços. Uma empresa responsável passa a assumir um papel de produtora de melhorias da qualidade de vida dos cidadãos, tornando, assim, a sociedade mais justa e humana.

\section{Gestão sustentável}

Gestão sustentável é um tema recente para a sociedade, para as empresas e também para a literatura. Entende-se por gestão sustentável "aquela que incorpora os valores do desenvolvimento sustentável nas organizações e nas metas corporativas das empresas" (JULIATTO; CALVO; CARDOSO, 2011, p. 174). É a integração de programas e práticas relacionadas ao meio ambiente, em um processo contínuo de melhoria da gestão.

No entanto, para se ter uma visão mais ampla sobre o tema, é necessário compreender previamente o conceito de desenvolvimento sustentável. A definição mais conhecida foi criada em 1987 pela Comissão Mundial sobre Meio Ambiente e Desenvolvimento, a qual divulgou o relatório de Brundtland, conhecido como Nosso Futuro Comum (Our Common Future). O relatório trouxe um conceito de sustentabilidade até hoje utilizado, que é "aquele que atende às necessidades do presente sem comprometer a possibilidade de as gerações futuras atenderem a suas próprias necessidades" (COMISSÃO MUNDIAL SOBRE MEIO AMBIENTE E DESENVOLVIMENTO, 1991).

A partir do surgimento do conceito de desenvolvimento sustentável, passou a existir um discurso cada vez mais articulado, que procura condicionar a busca de um novo modelo de desenvolvimento aliado à noção de conservação do meio ambiente. Assim, o desenvolvimento sustentável caracteriza-se como processo de transformação, no qual se busca a harmonização da exploração dos recursos, da direção dos investidores, da orientação do desenvolvimento tecnológico e da mudança institucional, a fim de reforçar o potencial presente e futuro do meio ambiente como suporte das atividades econômicas dessas populações, procurando melhor atender às necessidades, respeitando a livre determinação sobre a evolução de seus perfis culturais (SEIFFERT, 2009).

Complementando as definições abordadas acima, Savitz e Weber (2007, p. 2) afirmam que: 
O termo Sustentabilidade se originou da conscientização crescente, durante a década de 1980, de que os países precisavam descobrir maneiras de promover o crescimento de suas economias sem destruir o meio ambiente ou sacrificar o bem-estar das futuras gerações. Desde então, o termo sustentabilidade se transformou em mote de ampla gama de causas sociais e ambientais, sobretudo no mundo dos negócios, onde denota uma ideia poderosa e objetiva: empresa sustentável é aquela que gera lucro para os acionistas, ao mesmo tempo em que protege o meio ambiente e melhora a vida das pessoas com que mantém interações.

Dias (2009, p. 38) define desenvolvimento sustentável no meio empresarial como "[...] um modo das empresas assumirem formas de gestão mais eficientes, como práticas identificadas como eco-eficiência do empresariado em torno de uma perspectiva de um desenvolvimento econômico mais sustentável". Embora haja um crescimento perceptível da mobilização em torno da sustentabilidade, o foco ainda é no ambiente interno das organizações, voltadas prioritariamente para os processos e produtos.

A sustentabilidade empresarial pressupõe, então, que a empresa cresça, seja rentável e gere resultados econômicos, mas também contribua para o desenvolvimento da sociedade e para a preservação do Planeta. Esta é a definição do inglês John Elkington (2001), o qual criou o termo Triple Bottom Line (também conhecido pela sigla TBL), para se referir às três dimensões envolvidas na busca pela sustentabilidade: econômica, ambiental e social. A ideia central de Elkington é que as organizações avaliem o sucesso não somente com base no desenvolvimento financeiro, geralmente expresso em termos de lucro, mas na necessidade de avaliar também o impacto sobre a economia mais ampla, sobre o meio ambiente e sobre a sociedade em que a empresa atua.

Segundo Guarnieri (2011, p. 26),

[...] as práticas sustentáveis inseridas no contexto empresarial possuem o objetivo principal de reduzir os danos resultantes das atividades empresariais de forma a criar valor econômico, social e ambiental. O procedimento TBL evidencia com transparência o propósito da empresa neste sentido e considera as atividades dos autores envolvidos no processo, sejam eles proprietários, acionistas, fornecedores, prestadores de serviço, clientes, comunidade, poder público e sociedade em geral.

Tachizawa (2008) cita que a preservação do meio ambiente converteu-se em um dos fatores de maior influência nos anos 90 e na primeira década de 2000, com grande rapidez de penetração de mercado. Assim, as empresas começaram a apresentar soluções, para alcançar o desenvolvimento sustentável, e, ao mesmo tempo, aumentar a lucratividade de seus negócios. Nesse contexto, gestão sustentável não é apenas uma atividade filantrópica, ou tema para ecologistas e ambientalistas, mas também uma atividade que pode propiciar ganhos financeiros para as empresas.

O aumento da consciência ambiental e a escassez de recursos naturais vêm influenciando as organizações a contribuírem de forma sistematizada na redução dos impactos ambientais associados aos seus processos. Como consequência disso, foram criadas as normas da série ISO 14000, e, conforme Seiffert (2009, p. 16): [...] a importância das normas da série ISO 14000, e particularmente da ISO 14001, reside no fato de que estabelecem uma base comum para a gestão ambiental eficaz no mundo inteiro, sendo 
aplicável a organizações com mais variados perfis.

Em busca de padrões, como a ISO 14000, a gestão sustentável passa a ser a expressão utilizada para denominar a gestão empresarial que se orienta, para evitar, na medida do possível, problemas para o meio ambiente. Em outros termos, a gestão cujo objetivo é conseguir que os efeitos ambientais não ultrapassem a capacidade de carga do meio onde se encontra a organização, ou seja, é a que visa obter um desenvolvimento sustentável (DIAS, 2009).

Vale ressaltar que a sustentabilidade não significa meramente boa cidadania empresarial, isto é, ser reconhecida por reduzir a emissão de gases tóxicos, subsidiar benefícios aos funcionários e, muito menos, uma questão de ética nos negócios. Segundo Savitz e Weber (2007), a sustentabilidade é hoje princípio fundamental para uma gestão inteligente, algo muito fácil de ignorar ou de assumir como inevitável, num mundo em que o resultado financeiro geralmente é visto como a única medida de sucesso.

Dentro desse contexto, é possível considerar alguns exemplos de empresas brasileiras que já aderiram à prática da gestão sustentável. A Natura Cosméticos utiliza como estratégia sustentável o produto e o preço. A empresa adota o uso de refil em vários produtos de várias linhas, o que dá ao cliente a possibilidade de adquirir o mesmo produto da embalagem regular, com a mesma quantidade e qualidade, por um preço mais acessível e ainda contribuir para um impacto ambiental menor. O refil utiliza menos matéria-prima para ser produzido (em média, a metade da embalagem normal), ou seja, exige menos recursos da natureza para ser fabricado e gera menos resíduo depois de descartado (GESSI et al., 2010).

Outro caso de empresa sustentável é o da Petrobrás. No início de 2008, a Companhia foi reconhecida, através de pesquisa do Management \& Excellence, a petroleira mais sustentável do mundo, que tem como exemplo de produto e preço a Gasolina Podium. Esta gasolina, além de ser menos poluente, por conter menor teor de enxofre que as demais (30 ppm), ajuda na manutenção de todo o sistema de combustão (bicos injetores, válvulas de injeção, etc.) dos veículos. A Gasolina Podium pode ser utilizada em qualquer veículo, pois possui aditivos que têm a função de manter e limpar todo o sistema de alimentação de combustível do veículo. Quando o motor do veículo é mantido limpo, a sua vida útil é maior, e ele é menos poluente (GESSI et al., 2010).

E, por fim, um exemplo de empresa sustentável que tem práticas semelhantes às da empresa em estudo é a Wal-Mart Brasil, que possui um centro de distribuição ecoeficiente, inaugurado em 24 de agosto de 2009, localizado em Betim (MG). A inauguração desse centro reforça o compromisso da empresa com a sustentabilidade. Dentre as iniciativas sustentáveis do centro de distribuição, pode-se observar a eficiência no consumo de energia e de água, sendo esta uma das mais importantes. O prédio utilizará sistemas de energia renovável, através da luz solar, e também de captação de água da chuva, que será armazenada e filtrada para uso e reúso. Outras iniciativas do centro de distribuição ecoeficiente do país são controle automático da iluminação artificial, para o máximo aproveitamento; sistema de tratamento de esgoto; pavimentação permeável; energia solar para aquecimento da água (banheiros); gestão para resíduos; arquitetura adaptada a pessoas com deficiência física; utilização de biodiesel; estação de tratamento de água (para regar jardim) e outros (GESSI et al., 2010). 
Com a crescente preocupação da sociedade em torno das ações que minimizem danos ao meio ambiente, as empresas de tecnologia da informação também estão se conscientizando e aderindo a meios mais sustentáveis; dessa maneira, por ser o assunto foco deste trabalho, o capítulo seguinte irá tratar das considerações acerca da tecnologia sustentável, com o objetivo de oferecer melhor entendimento ao leitor.

Ressalta-se que, atualmente, os assuntos relacionados à tecnologia e sustentabilidade estão ganhando destaque e ocupando um importante espaço na sociedade e também nas organizações empresariais. Conforme o tempo foi passando, aumentou consideravelmente o uso de computadores por parte das empresas e também para uso pessoal. A quantidade de dados e informações que podem ser armazenados e computados fez com que o uso de computadores se tornasse indispensável. Então, a informática surgiu para superar a necessidade do ser humano de registrar e manipular dados em grandes quantidades com precisão e rapidez.

A todo instante, são lançados no mercado computadores modernos, rápidos e com novas tecnologias. Na medida em que esses computadores ficam mais modernos, com uma capacidade maior de processamento, eles precisam de mais energia para conseguir processar tais informações com maior rapidez. Conforme Aguilar (2009, p. 14):

O elevado índice de produção de microcomputadores, aliado a um aumento constante de número de consumidores sedentos por tecnologia, resultou em uma preocupação que antes não tínhamos: reciclar ou buscar novas alternativas para os materiais componentes de computadores, pois os recursos utilizados estão gradativamente mais escassos, e a matéria-prima para a produção destes componentes está se esgotando.

Diante dessa situação, é importante criar e estabelecer práticas que busquem reduzir o desperdício e aumentar a eficiência de todos os processos e fenômenos relacionados à operação de computadores. O conjunto de práticas, para tornar mais sustentável e menos prejudicial o uso da computação, é conhecido como TI Verde.

Para Silva et al. (2010, p. 2), TI Verde “[...] é uma expressão que tem sido utilizada pelo setor de tecnologia para incorporar a preocupação com o meio ambiente e a sustentabilidade". Essa expressão é a soma de economia de energia com gestão de recursos, desde as cadeias produtivas e todo o ciclo, que vai da extração de matéria-prima até o final da vida útil do equipamento, incluindo o seu descarte. Assim, a TI Verde também pode trazer retorno financeiro para as empresas ao ter como objetivo economizar recursos, ou reduzir gastos de energia.

Portanto, gestos como separar os resíduos, programar as impressoras para imprimir frente e verso e reutilizar folhas de papel são atitudes fáceis de serem implementadas, porém o mais difícil é conscientizar a todos da sua importância e mudar-lhes os hábitos.

\section{A importância da sustentabilidade na gestão empresarial}

Este capítulo apresenta os resultados obtidos por meio da pesquisa, utilizando-se da metodologia proposta, visando atender ao objetivo geral e aos específicos descritos no projeto. Dessa forma, a análise tem como objetivo descrever como foi a implantação de 
um projeto de sustentabilidade numa empresa do ramo de tecnologia da informação, identificando as ações executadas e os resultados esperados pelos gestores.

A forma de coleta de dados, neste primeiro momento, partiu das análises de documentos e de entrevistas realizadas com os colaboradores da empresa. Os dados foram coletados por meio de uma entrevista semiestruturada, contendo oito questões abertas, dando aos entrevistados liberdade de expor suas opiniões de acordo com seu ponto de vista. Além disso, foi aplicada uma entrevista fechada com os funcionários da empresa, com o objetivo de verificar o seu conhecimento sobre o "Programa Verde".

Com relação à entrevista semiestruturada, os entrevistados são colaboradores da empresa em estudo, sendo um o coordenador da assessoria de comunicação, responsável pelas matérias divulgadas a respeito do projeto de sustentabilidade; o outro, coordenador da assessoria executiva, o qual participou, desde o início, da implantação deste projeto na empresa. O último entrevistado, o supervisor de recursos humanos, contribuiu fazendo uma análise focada nas pessoas, observando como os funcionários reagiam em relação às mudanças ocorridas na empresa.

Na primeira questão, foi abordado o conceito de sustentabilidade, integrando as dimensões econômica, social e ambiental, e o modo de transferência desse conceito para os processos e para a rotina da companhia. As entrevistas denunciaram que o objetivo da implantação de um projeto sustentável é conduzir a companhia pelos caminhos da sustentabilidade, tendo como meta enquadrar a empresa no conceito de TI Verde, devido à natureza de suas atividades. Para isso, foram realizadas atividades dirigidas a servidores e gerentes, no sentido de despertar-Ihes o envolvimento, a conscientização e a motivação pelas práticas de sustentabilidade, numa clara mensagem de que todos são peças fundamentais para o andamento do processo.

Em relação à primeira questão, o coordenador da assessoria de imprensa relatou a realização de "[...] palestras, oficinas, dentro do próprio ambiente de trabalho, e, ainda, uma ação específica, que motivou alunos da rede municipal de ensino a escreverem sobre lixo eletrônico, as quais ajudaram a formar a base da proposta para elaboração do projeto". Somente após essa etapa, as ações geradoras de consumo eficiente, consciência de reaproveitamento e alternativas para diminuição de poluentes atmosféricos foram efetivamente inseridas na rotina da empresa.

Quando questionado sobre as ações e práticas sustentáveis a que a companhia aderiu, os três entrevistados relataram, de modo geral, todas as mudanças que houve na empresa, após a implantação do projeto de sustentabilidade, sendo elas:

- Instalação de filtros antispam: a empresa reduziu, em média, 300 mil gramas, por dia, de sua emissão de gás carbônico na atmosfera, com a implantação de ferramenta antivírus-antispam nos servidores, que administram cerca de 24 mil endereços de correio eletrônico da prefeitura municipal de Porto Alegre. A iniciativa verde reduziu, ainda, o tempo que os colaboradores e usuários gastam lendo e apagando mensagens indesejadas;

- Desenvolvimento do sistema de distribuição de documentação eletrônica: este sistema foi desenvolvido com o intuito de diminuir a quantidade de relatórios gerados pela empresa à prefeitura municipal, como folhas de pagamen- 
to, IPTU, ISSQN, entre outros. De toda a estrutura que o município utilizava, em média 15 caixas de papel por mês, hoje o montante impresso foi reduzido em $80 \%$. As 150 mil folhas de papel foram reduzidas a 30 mil atualmente;

- Utilização de monitor LCD: para reduzir o consumo de energia da companhia, que tem em média 500 micros, a empresa trocou 98\% dos monitores convencionais, de tubo (CRT), por telas de cristal líquido (LCD). O monitor CRT tem consumo muito maior, em média $80 \mathrm{w}$, enquanto o LCD gasta cerca de $35 \mathrm{w}$. Os monitores LCD, além de utilizarem menos energia que os monitores CRT, emitem menos calor e contribuem para a economia do sistema de ar condicionado;

- Projeto Mainframe ${ }^{6}$ : A aquisição do novo mainframe IBM System Z9, ainda em 2008, alinhou-se ao ambiente verde de responsabilidade ambiental da empresa. O equipamento consome cerca de $30 \%$ menos energia e tem performance cerca de 10 vezes superior;

- Infovia verde: em 2013, a empresa atingiu mais de 900 quilômetros de fibra óptica, 458 quilômetros de dutos e 16 torres de transmissão. A companhia orgulha-se de ter baseado o crescimento de sua infraestrutura na compatibilização do desenvolvimento econômico-social com a preservação da qualidade do meio ambiente e do equilíbrio ecológico, visando ao desenvolvimento sustentável. O resultado é uma infovia verde que utiliza corretamente as vias públicas, otimizando o espaço público subterrâneo e evitando a proliferação de escavações nas ruas de Porto Alegre;

- Redes Wireless: a rede wireless dispensa o uso de cabos e oferece a mobilidade sem fio para alcançar os locais onde a fibra não chega. Mas a obtenção de informações, em tempo real, que pressupõe maior produtividade, também tem sua contribuição verde;

- Gerenciamento remoto: a empresa adotou a prática de gerenciamento remoto em computadores, gerando economia de combustível, diminuição de emissão de $\mathrm{CO}_{2}$, já que evitou, com isso, 14,8 mil deslocamentos de técnicos na cidade. Esse gerenciamento foi possível através da instalação de um software chamado Trauma Zero, que possibilita a centralização dos dados com segurança e controle das informações;

- Iluminação natural: reforma de ambientes, com ampliação de janelas e paredes de vidro, ampliando a oferta de luminosidade natural e diminuindo o consumo de energia elétrica;

- Iluminação artificial eficiente: troca da rede elétrica, com reatores de baixo consumo, e troca da rede elétrica do Datacenter. A substituição do sistema de iluminação foi feita em $80 \%$ da empresa e representou uma economia de $42 \%$ na conta da energia elétrica;

- Sensores de presença: instalados em pontos estratégicos, como áreas de cir-

${ }^{6}$ Mainframe é um computador de grande porte, dedicado normalmente ao processamento de um volume de grandes informações. 
culação interna e banheiros. As lâmpadas acendem automaticamente, quando detectam a presença de movimento, e desligam-se quando a pessoa sai do local. Esta iniciativa garante a economia de energia elétrica;

- Climatização: o sistema de ar-condicionado da empresa foi completamente reformulado dentro do procedimento de melhorias com vistas ao consumo eficiente de energia e à qualificação dos espaços. Todos os condicionadores de ar de janelas foram substituídos por equipamentos de parede modelo split, silenciosos e funcionais, e que representam maior capacidade de refrigeração e maior economia em quantidade de $\mathrm{KW} / \mathrm{h}$;

- Modernização no consumo de água: o monitoramento do consumo de água também entrou na lista de prioridades da companhia. Por isso, a empresa investiu em ampla reforma nos oito banheiros, para reparos de vazamentos e melhorias de piso, azulejos e louças sanitárias;

- Torneiras econômicas: a obra substituiu torneiras convencionais de mictórios por modelos com sensores de presença. Nos lavatórios, foram instaladas torneiras economizadas com redutores de vazão, garantido consumo mínimo de água e conforto aos usuários;

- Mais controle de papel: outra medida que imprimiu consumo eficiente nos banheiros da empresa foi a substituição dos toalheiros simples por modelos com sistema por alavanca e picote automático, diminuindo o desperdício de papel na companhia;

- Gerenciamento do papel: considerando a gestão eficiente do papel como fator importante para a economia dos recursos naturais, a empresa realiza duas ações pontuais: doação e reutilização das folhas usadas. Ao invés de ir para o coletor, o papel tem sua vida útil prolongada. Parte dele, com anotações internas, transforma-se em blocos de rascunho. A outra parte é doada para escolas municipais e hospitais, que reutilizam o lado inverso para diferentes fins;

- Separação de resíduos: A empresa incentiva a separação de resíduos com a disponibilização de coletores adequados em cada estação de trabalho. Os sacos verdes são destinados ao resíduo seco, enquanto os coletores com saco laranja são reservados aos resíduos orgânicos. A atitude é simples, porém de grande valor, pois facilita o trabalho de quem faz a coleta seletiva. A empresa possui um convênio com o Departamento Municipal de Limpeza Urbana (DMLU), que faz a coleta e destina corretamente os resíduos secos e orgânicos produzidos pela empresa;

- Lixo eletrônico: a empresa, em parceria com outras secretarias da prefeitura municipal, promove a coleta de lixo eletrônico. São recolhidos materiais como monitores, teclados, impressoras, pilhas, entre outros. Parte do material é consertado e doado a instituições carentes, e o restante é destinado a empresas de reciclagem;

- Doação de computadores: a companhia realiza doações de todo material que deixa de ser utilizado pela organização. No total, foram destinados 1.085 com- 
ponentes de informática, entre eles, 418 monitores, 393 teclados, 178 impressoras, 54 mouses, 12 notebooks, entre outras peças, como periféricos, servidores de pequeno porte e equipamentos de rede. Todo material está sendo reaproveitado por associações, instituições ou escolas criadas especialmente para as pessoas que mais precisam.

Outra questão analisada é se a empresa possui algum projeto de reaproveitamento e recolhimento sustentável de equipamentos obsoletos. Através da entrevista, ficou esclarecido que a empresa, desde dezembro de 2010, é ponto permanente de recolhimento de resíduos eletrônicos. Qualquer cidadão pode descartar seu resíduo tecnológico na empresa. O material é armazenado até que atinja uma quantidade significativa para ser encaminhado ao descarte correto em empresas conveniadas e especializadas em reciclagem. A parceria com o DMLU mostra que é possível o poder público incentivar ações que impulsionem o correto descarte desses resíduos, que chegam a 40 milhões de toneladas por ano no mundo, conforme a Organização das Nações Unidas - ONU (2010). A empresa faz também coleta especifica de fios e cabos obsoletos e encaminha esse material para uma empresa que devolve uma quantidade proporcional em cabos novos, com a finalidade única de colocar cabeamentos de internet nas escolas municipais de Porto Alegre.

Os entrevistados foram questionados sobre o que eles observaram de diferente na empresa em nível de custo/benefício. Segundo o coordenador da assessoria de comunicação,

foram observados especialmente os reflexos de redução de despesas financeiras. O montante investido, por exemplo, na ampliação de janelas, paredes de vidro, dispensadores automáticos de papéis-toalha, sensores de presença, equipamentos mais modernos de climatização de ambiente e até mesmo em seminários e oficinas, vem justificando-se, a cada mês, com a sensível diferença no consumo de muitos itens.

Também foi perguntado aos entrevistados se a empresa já obteve retorno dos investimentos feitos na implantação do projeto de sustentabilidade. Esta é uma questão bem divulgada na organização, porque, além da economia, a companhia já recebeu, por quatro vezes, a distinção Agradecimento Green IT da multinacional japonesa Furukawa, por ter ajudado o planeta em sua preservação ambiental. Com suas ações focadas na sustentabilidade, a empresa evitou que muitas toneladas de materiais contaminados com metais pesados fossem depositadas em aterros industriais. E, ainda, recebeu fios e cabos novos, com destinação dirigida às escolas municipais de Porto Alegre, sendo que, de cada 100 quilos de fios e cabos enviados para reciclagem, a empresa recebe de volta 305 metros de cabos novos.

Quando questionados se os gestores da empresa receberam algum tipo de feedback por parte dos funcionários em relação à implantação do projeto, foi respondido que "o 'feedback' ainda está aquém do esperado". Mesmo depois de tanto tempo e com o oferecimento de situações que favorecem a aplicabilidade de uso racional e até mesmo políticas de descarte correto de sucatas e/ou materiais obsoletos, os servidores, em sua maioria, não executam na totalidade as propostas que almejam a qualificação da com- 
panhia como uma empresa com responsabilidade ambiental.

Conforme a coordenadora da assessoria executiva, no início do Programa Verde, em 2009, houve contato pessoal com todos os gerentes e supervisores, para identificar iniciativas em andamento que se enquadrassem no conceito de TIC Verde, a fim de que fossem incluídas no Programa. Ainda, abriu-se canal via internet para o recebimento de sugestões e colaborações.

Entretanto, na visão dela, é preciso admitir que ainda há muito a fazer para despertar a conscientização dos colaboradores. Exemplo disso é a simples separação de resíduos secos e orgânicos, que deixa a desejar, mesmo que em todos os ambientes existam coletores distintos por cores e ainda recipientes especialmente destinados para o descarte de erva-mate. Outra observação são as folhas impressas, cujo verso pode ser reutilizado para confecção de blocos ou encaminhamento a entidades educacionais. 0 número de impressões reduziu sensivelmente, mas ainda há muito papel que pode ser reaproveitado e que está sendo jogado fora sem a devida reutilização.

Quando questionados se a companhia serviu como modelo para outras empresas, após a implantação do projeto de sustentabilidade, foi respondido que, em 2012, a companhia recebeu um grupo de representantes da empresa Leroy Merlin (loja de materiais de construção e decoração).

A vinda da empresa visou à troca de experiências relativas às práticas de gestão sustentável. Por meio de seu projeto Visão 2020, a Leroy criou um roteiro de visitas a empresas, ONG's e órgãos públicos que já estavam sendo consolidados como referências em tecnologia e também em sustentabilidade.

A empresa pesquisada apresentou aos representantes da Leroy Merlin ações do "Programa Verde", através das quais vem buscando diminuir o impacto ambiental, com iniciativas concretas, para a diminuição no consumo e o uso mais eficiente de energia elétrica, água e papel, entre outras, como a colocação de sensores nas torneiras, nos dispensadores de tolhas de papel, sensores de presença, o que foi fundamental para os resultados positivos nas metas do Programa Verde.

A última pergunta da entrevista semiestruturada é mais voltada para os gestores da companhia, pois questiona o que os motivou a adotar práticas sustentáveis na rotina da empresa. Mas, como não foi possível aplicar esta entrevista ao presidente da empresa, sendo ele o responsável pela implantação do projeto de sustentabilidade, os outros colaboradores participantes desta pesquisa responderam de forma genérica sobre o tema, mas não especificamente sobre a implantação do projeto de sustentabilidade.

Para complementar a pesquisa, incluiu-se algumas perguntas com a finalidade de revelar a visão dos funcionários sobre o Programa Verde.

Foi aplicado um questionário fechado, contendo seis questões, a um pequeno grupo de dez funcionários da empresa em estudo, para visualizar a opinião deles em relação ao projeto implantado na organização. 
Segue o quadro com as constatações a partir das questões aplicadas.

Quadro 1 - Resumo das respostas da visão dos funcionários sobre o Programa Verde
\begin{tabular}{|l|c|c|c|}
\hline \multicolumn{1}{|c|}{ Questões } & $\begin{array}{c}\text { Sim } \\
(\%)\end{array}$ & $\begin{array}{c}\text { Não } \\
(\%)\end{array}$ & $\begin{array}{c}\text { Outros } \\
\text { (\%) }\end{array}$ \\
\hline $\begin{array}{l}\text { 1 - Você tem conhecimento do programa de } \\
\text { sustentabilidade implantado na empresa? }\end{array}$ & 60 & 40 & - \\
\hline $\begin{array}{l}\text { 2 - A empresa realiza campanhas sobre sustentabilidade } \\
\text { e cuidados com o meio ambiente? }\end{array}$ & 40 & 60 & - \\
\hline $\begin{array}{l}\text { 3 - A companhia procura reduzir a produção de resíduos } \\
\text { (por exemplo: evita copos plásticos e reutiliza papel)? }\end{array}$ & 60 & 30 & 10 \\
\hline $\begin{array}{l}4 \text { - A empresa disponibiliza pontos de coletas de } \\
\text { materiais para reciclagem e coletores de resíduos? }\end{array}$ & 100 & - & - \\
\hline $\begin{array}{l}5 \text { - A empresa estimula os colaboradores a contribuírem } \\
\text { para a redução de resíduos e desperdícios? }\end{array}$ & 80 & 20 & - \\
\hline $\begin{array}{l}\text { 6 - Você acha positivo um projeto de sustentabilidade } \\
\text { na empresa? }\end{array}$ & 100 & - & - \\
\hline
\end{tabular}

Fonte: Dados da pesquisa (2013).

Conforme mostra o quadro, a primeira questão buscava saber se os funcionários tinham conhecimento do programa de sustentabilidade implantado na empresa: $60 \%$ responderam sim, e 40\% responderam não. Dois dos entrevistados que tinham conhecimento do projeto citaram o nome, e um dos respondentes alegou não conhecê-lo, por não ter um setor específico que atue na divulgação do Projeto Verde entre os funcionários.

$\mathrm{Na}$ segunda questão, que trata da realização de campanhas educativas sobre sustentabilidade, $40 \%$ responderam que sim, que a empresa promove campanhas educativas e que as divulga através de folders, e $60 \%$ responderam que não. Na terceira questão, a qual questiona se a empresa procura reduzir a produção de resíduos, $60 \%$ responderam que sim, que até foi distribuída aos funcionários uma caneca, para diminuir a utilização de copos plásticos; $30 \%$ responderam que não e justificaram que falta consciência e atitude por parte dos funcionários, e 10\% não responderam.

Na quarta questão, foi questionado se a empresa disponibiliza pontos de coletas e coletores de resíduos, e a resposta foi $100 \%$ sim, justificando que a empresa estimula os funcionários a reciclarem os resíduos, disponibilizando coletores específicos para cada tipo de resíduo, inclusive de lixo eletrônico. Na quinta questão, foi perguntado se a empresa estimula os colaboradores a contribuírem para a redução de resíduos. Os resultados dessa pergunta tiveram $80 \%$ de respostas positivas, justificando que a empresa se utiliza de campanhas de estímulo, e $20 \%$ de respostas negativas. 
A última questão vislumbra a posição do funcionário, se ele acha positivo esse tipo de projeto na empresa. A resposta foi $100 \%$ positiva, e dois funcionários citaram que as empresas estão se preocupando mais com o meio ambiente, e que "pequenos gestos significam grandes mudanças".

\section{Considerações finais}

O presente trabalho procurou demonstrar a importância de uma empresa do ramo de tecnologia da informação e comunicação adotar uma gestão preocupada com o ambiente e com a responsabilidade social. Através das informações obtidas e das mudanças ocorridas na empresa, pode-se observar que a companhia em estudo se preocupa com o meio ambiente e com sua imagem perante a sociedade e os seus clientes.

O objetivo da empresa é alinhar-se às melhores práticas de sustentabilidade e à excelência na administração pública, considerando o crescimento sustentável como um importante componente da responsabilidade socioambiental.

Por isso, a companhia quer praticar e incentivar, cada vez mais, as ações que busquem a convergência de seus objetivos de inovação tecnológica com os interesses da prefeitura municipal e da sociedade, sempre em harmonia com o meio ambiente, promovendo o crescimento sustentável e otimizando os recursos naturais.

Mas não adianta só o incentivo dos gestores, para uma empresa ser sustentável, são necessários a colaboração e o comprometimento de todos os seus servidores. Como foi observado na análise dos dados, os funcionários, na sua maioria, não colaboram com o andamento do projeto, já que um simples gesto, como separar os resíduos e reutilizar os papéis, não é feito corretamente.

No desenvolvimento da pesquisa, porém, surgiram dificuldades relacionadas à coleta de dados. A empresa passou por um processo de reestruturação em que houve uma grande mudança no quadro funcional da companhia, sendo que os gestores responsáveis pela implementação do projeto de sustentabilidade, que seriam peças fundamentais para a pesquisa, saíram da empresa sem deixar contato.

No entanto, a utilização da empresa como referência para este artigo deve-se ao fato da companhia ser reconhecida no seu mercado de atuação e, além disso, ter uma importância para a cidade de Porto Alegre, tanto no setor público como no privado, pelos serviços prestados a esses clientes. A companhia, com a intenção de ser uma empresa referência no seu ramo de atividade, está comprometida com a utilização de ações e soluções que diminuam o impacto da tecnologia no meio ambiente. Por isso, a rotina da empresa é planejada para ter menor fluxo de processamento, utilizando menos energia e calor.

Desse modo, o foco na eficiente economia de recursos naturais passa a ser o lema da empresa em estudo. A preocupação da companhia é criar ambientes de trabalho mais verdes, priorizando soluções sustentáveis. Assim, uma das principais vantagens associadas ao conceito verde de gestão de negócios em TI é a economia de energia. O fato se deve, em grande parte, ao avanço das tecnologias de virtualização e desenvolvimento de máquinas cada vez menos dependentes e consumidoras de energia.

Portanto, a companhia passa a ter um novo olhar sobre tudo que diz respeito à sua interferência e à relação com o meio ambiente. $E$, além de investimentos verdes 
nas tecnologias que opera e operacionaliza, promove ações amigáveis também na sua estrutura interna.

Por fim, foi possível identificar que os objetivos propostos na pesquisa foram atingidos. Percebe-se que a empresa em estudo aplicou os conceitos de sustentabilidade e responsabilidade social, na sua rotina de trabalho, conforme questionamento no problema de pesquisa. É possível identificar e visualizar todas as mudanças ocorridas na empresa, desde a troca de equipamentos eletrônicos antigos por equipamentos novos, que consomem menos energia, até a reutilização de materiais e separação adequada de resíduos.

\section{Referências}

ASSOCIAÇÃO BRASILEIRA DE NORMAS TÉCNICAS. ABNT. NBR ISO 26000: 2010. Disponível em: <http://www.abnt.org.br/m3.asp?cod_pagina=1006>. Acesso em: 15 out. 2013.

AGUILAR, Fabio Pacheco. Tecnologia da informação verde. Uma abordagem sobre investimentos e atitudes das empresas para tornar socialmente sustentável o meio ambiente. 2009. Disponível em: <http://fateczl.edu.br/TCC/2009-2/tcc-23.pdf>. Acesso em: 8 ago. 2013.

COMISSÃO MUNDIAL SOBRE MEIO AMBIENTE E DESENVOLVIMENTO. CMMAD. NosSo Futuro Comum. 2. ed. Rio de Janeiro: Fundação Getúlio Vargas, 1991.

DIAS, Reinaldo. Gestão Ambiental: Responsabilidade Social e Sustentabilidade. São Paulo: Atlas, 2009.

DONAIRE, Denis. Gestão Ambiental na Empresa. 2. ed. São Paulo: Atlas, 1999.

ELKINGTON, John. Canibais com garfo e faca. São Paulo: Makron Books, 2001.

FREEMAN, Edward R. Strategic managemente: a stakeholder approach. Boston: Pitman Publishing, 1984.

GESSI, Liliana et al. O composto de marketing e a estratégia da sustentabilidade: análise de cases em empresas. 2010. Disponível em: <http://redcidir.org/multimedia/ pdf/trabajos_seleccionados/Seleccionados-III-Simposio/Asociativismo-empresas-e-innovaci\%C3\%B3n/oCdeMeaEdaS.pdf>. Acesso em: 15 out. 2013.

GUARNIERI, Patrícia. Logística Reversa: em busca do equilíbrio econômico e ambiental. Recife: Clube dos Autores, 2011.

INSTITUTO DE EMPRESA E RESPONSABILIDADE SOCIAL. Instituto Ethos. Norma ISO 26000: Responsabilidade Social. Disponível em: <http://www3.ethos.org.br/cedoc/ incorporacao-dos-principios-da-responsabilidade-social/\#.UXASW6KG2Sp>. Acesso em: 2 abr. 2013.

JULIATTO, Luiz D.; CALVO, Milena J.; CARDOSO, Elpídio T. Gestão Integrada de Resíduos Sólidos para Instituições Públicas de Ensino Superior. 2011. Disponível em: $<$ https://periodicos.ufsc.br/index.php/gual/article/download/1983-4535.2011v4n3p170/21985>. Acesso em: 10 out. 2013. 
ORGANIZAÇÃO DAS NAÇÕES UNIDAS. ONU. Geração de lixo eletrônico cresce a 40 milhões de toneladas pro ano. Folha de São Paulo. Disponível em: <http://www1.folha. uol.com.br/folha/ambiente/ult10007u697099.shtml>. Acesso em: 15 out. 2013.

SAVITZ, Andrew W.; WEBER, Karl. A Empresa Sustentável. O verdadeiro sucesso é o lucro com responsabilidade social e ambiental. Rio de Janeiro: Elsevier, 2007.

SEIFFERT, Mari Elizabete Bernardini. ISO 14001 sistemas de gestão ambiental: implantação objetiva e econômica. 3. ed. São Paulo: Atlas, 2009.

SILVA, Manoel R. et al. Ti Verde: Princípios e práticas para aplicação em universidades. 2010. Disponível em: <http://labplan.ufsc.br/congressos/III\% 20SBSE\%20-\%202010/ PDF/SBSE2010-0085.PDF>. Acesso em: 5 ago. 2013.

TACHIZAWA, Takeshy. Gestão ambiental e responsabilidade social corporativa: estratégias de negócio focadas na realidade brasileira. 5. ed. São Paulo: Atlas, 2008.

WANDERS, Markus. Datacenter verde: como reduzir o impacto ambiental. Disponível em: <http://www.unit.br/publica/2011.1/cdg_ext_02_data_center_verde.pdf>. 2011. Acesso em: 18 abr. 2013. 